\title{
Risk factors of portal vein thrombosis after splenectomy in patients with liver cirrhosis
}

\author{
Ze-long Yang', Ting Guo², Dong-Lie Zhu', Shi Zheng', Dan-Dan Han', Yong Chen'1 \\ 'Department of Hepatobiliary Surgery, Xijing Hospital, Fourth Military Medical University, Xi'an 710032, Shaanxi, China. \\ ${ }^{2}$ Department of Obstetrics, Huaxi Hospital, Sichuan University, Cheng Du 610011, Si Chuan, China.
}

Correspondence to: Yong Chen, PhD, Chief Physician, Department of Hepatobiliary Surgery, Xijing Hospital, Fourth Military Medical University, 127 West Changle Road, Xincheng District, Xi'an 710032, Shaanxi, China. E-mail: gdwkcy@fmmu.edu.cn

How to cite this article: Yang ZL, Guo T, Zhu DL, Zheng S, Han DD, Chen Y. Risk factors of portal vein thrombosis after splenectomy in patients with liver cirrhosis. Hepatoma Res 2020;6:37. http://dx.doi.org/10.20517/2394-5079.2020.09

Received: 31 Jan 2020 First Decision: 13 Apr 2020 Revised: 4 May 2020 Accepted: 10 Jun 2020 Published: 10 Jul 2020

Academic Editor: Guang-Wen Cao, Guido Guenther Gerken Copy Editor: Cai-Hong Wang Production Editor: Tian Zhang

\begin{abstract}
Portal vein thrombosis (PVT) is a common complication after splenectomy, causing a possible negative impact on the prognosis of patients with liver cirrhosis. However, the risk factors of PVT are not completely clear. Many factors are related to the occurrence of postoperative PVT, such as hemodynamic changes, splenomegaly, splenectomy, coagulation and anticoagulation disorder, liver cirrhosis, platelet count, D-dimer level, infection, inflammation, and other factors. Hemodynamic changes are mainly caused by thicker portal and splenic vein diameters, larger spleen, slower portal vein blood flow rate, lower portal vein pressure before and after surgery, etc. It is timely detection and advanced prevention that really matter in reducing PVT incidence and improving patient prognosis. We systematically reviewed the researches on the risk factors and therapies of PVT to provide useful information on a comprehensive understanding for researchers.
\end{abstract}

Keywords: Liver cirrhosis, splenectomy, portal vein thrombosis, risk factors, treatments, prophylaxis

\section{INTRODUCTION}

Portal vein thrombosis (PVT) after splenectomy is a common postoperative complication, which has nonspecific clinical manifestation ${ }^{[1]}$, including fever, anorexia, abdominal pain, abnormal liver function, elevated C-reactive protein level, etc. As PVT progresses, complications can be worse and finally result in liver function deterioration, intestinal infarction and even intestinal necrosis ${ }^{[2-4]}$, making the mortality rate of PVT even up to $10 \%{ }^{[5]}$. The incidence of PVT after splenectomy in patients with cirrhosis and portal hypertension is reported to range $24 \%$ to $29 \%{ }^{[6,7]}$. For those who undergo splenectomy or accepted liver transplantation, early prevention of PVT is quite important to improve prognosis, which requires a full understanding of the risk factors of PVT. But so far, the risk factors of PVT still remain controversial. 


\section{RISK FACTORS}

\section{Hemodynamic changes}

Hemodynamic changes are considered to be the most important risk factor in the pathogenesis of PVT. The formation of pseudolobules in the liver can reduce portal blood flow velocity markedly, causing obstructed portal blood flow, increased portal pressure, and decreased blood flow velocity ${ }^{[8]}$. It can be said that the hemodynamic changes caused by the primary disease lays the foundation for the development of PVT.

Splenic vein diameter (SVD) is thought to be the most influential risk factor. A retrospective trail conducted in China found that 8 factors including the SVD are associated with postoperative PVT formation ${ }^{[9]}$. SVD greater than $10 \mathrm{~mm}$ has been a cut-off for predictors of PVT development and those greater than $14 \mathrm{~mm}$ has been a cut-off for predictors of PVT which develops from splenic vein ${ }^{[10]}$. Some authors even suggest that preoperative SVD greater than $8 \mathrm{~mm}$ is an independent risk factor for predicting $\mathrm{PVT}^{[11]}$. SVD is inversely related to the rate of change in portal blood flow, and its sensitivity, specificity and efficiency vary with the study's setting $^{[6]}$. In addition, spleen weight, discussed below, shows a significant correlation with SVD, where removal of an enlarged spleen may cause a sudden decrease in splenic vein flow, forming and pushing the thrombus to migrate to the portal vein. But compared with the weight of the spleen, SVD plays a greater role in predicting PVT. Some researchers recommend the measurement of SVD preoperatively, and a close follow-up of patients with SVD greater than $8 \mathrm{~mm}^{[12]}$.

Generally, for patients with decompensated cirrhosis, PVD is proportional to the degree of portal hypertension, and once it is determined that PVD is greater than $13 \mathrm{~mm}$, portal hypertension is considered to exist, and PVD is the independent risk factor of $\mathrm{PVT}^{[9]}$. Multivariate analysis in some studies certify the significant relationship between pathogenesis of PVT and a series factors, including wider preoperative PVD, of which the cut-off width was determined to be $13 \mathrm{~mm}^{[13]}$. Similarly, in another study, the incidence of PVT in patients with a PVD $>13 \mathrm{~mm}$ was 35 times that of others with $\mathrm{PVD}<13 \mathrm{~mm}^{[14]}$. When PVD becomes larger, blood flow velocity decreases, and the formation of blood clot is easier.

But some researchers believe that portal blood flow velocity is the only independent risk factor for PVT formation, and when velocity is lower than $15 \mathrm{~cm} / \mathrm{s}$, the risk of PVT increases significantly ${ }^{[15]}$. By dividing cirrhotic patients into two groups according to portal vein flow velocity ( $\leq 15 \mathrm{~cm} / \mathrm{s}$ or $>15 \mathrm{~cm} / \mathrm{s}$ ), the incidence of PVT within one year after surgery for the two groups turns out to be $47.8 \%$ and $2.0 \%$, respectively ${ }^{[14]}$. In a study examining the risk factors of PVT after the Hassab procedure, the cut-off points for portal vein flow, SVD and PVD were $1822.32 \mathrm{~mL} / \mathrm{min}, 1.37 \mathrm{~cm}$, and $1.56 \mathrm{~cm}$, respectively ${ }^{[16]}$. Besides, varicose veins of the esophagus and stomach caused by portal hypertension are also independently associated with the development of $\mathrm{PVT}^{[17]}$, and the wider portal collaterals can shunt more blood from the portal vein, slowing portal vein blood flow, and may increase the risk of $\mathrm{PVT}^{[14]}$. Slow blood flow not only causes the procoagulant substances in the blood to be slowly concentrated locally ${ }^{[18]}$, but also causes an increase in pressure on the blood vessel wall according to Bernoulli's principle, which will damage the endothelial cells and initiate the coagulation mechanism ${ }^{[3,19]}$. Therefore, it can be concluded that the wider PVD and SVD, the slower the blood flow of the portal vein system after operation and the greater the possibility of thrombosis ${ }^{[20]}$.

\section{Splenomegaly}

Splenomegaly is common in patients with liver cirrhosis, and patients with splenomegaly are at high risk of PVT; splenomegaly was previously thought to be related to passive congestion caused by portal hypertension ${ }^{[21]}$. However, there is no necessary correlation between portal vein pressure and spleen size, because the grown spleen does not retract, and hypersplenism is not relieved after transjugular intrahepatic portal body shunt (TIPS) or splenorenal shunt ${ }^{[22]}$. During years of follow-up of liver transplant recipients, portal pressure remained normal, but spleen enlargement persisted ${ }^{[2]}$. Despite that passive congestion may 
be one cause of the early stage of splenomegaly, there are still many causes to maintain splenomegaly, such as abnormal hyperplasia of white pulp, red pulp and fibrous tissues ${ }^{[23]}$.

Splenomegaly reduces the greater portal vein return flow after operation, inducing platelet aggregation ${ }^{[18]}$. It has been reported that spleen weight $(>650 \mathrm{~g})$ is associated with the development of $\mathrm{PVT}^{[24]}$ and that spleen weight $(\geq 1311.5 \mathrm{~g})$ is a significant independent predictor of PVT ${ }^{[25]}$. Patients with PVT had a significantly greater splenic weight $\left(\right.$ median $=216 \mathrm{~g}$ ) than those without PVT $(\text { median }=82 \mathrm{~g})^{[26]}$, and some authors suggest that spleen weight is the only predictive factor of postoperative thrombosis after laparoscopic splenectomy $(\mathrm{LS})^{[27]}$. Here, there is a consensus among researchers that an increasingly larger and heavier spleen would finally be able to cause PVT after splenectomy if there is no medical intervention ${ }^{[28]}$. Splenomegaly is a useful indicator of PVT, which can be conveniently evaluated before splenectomy by computed tomography ${ }^{[10]}$.

\section{Splenectomy}

Splenectomy is a major risk factor of PVT. Patients after splenectomy have a significantly higher incidence rate of PVT than those who have not undergone splenectomy ${ }^{[29]}$. During the operation, the use of cutting tools and ligation causes thermal or mechanical damage to vascular endothelial cells, inducing thrombus formation $^{[30,31]}$. Different surgical procedures cause different levels of PVT risk. In China, the Hassab operation has been adopted widely because of the benefits it brings and less tissue damage compared with shunt surgery ${ }^{[32]}$, but some clinicians believe that selective decongestive devascularization combined with gastrosplenic shunt is superior to the Hassab operation, because this surgical method results in a lower longterm incidence of re-bleeding and PVT compared with the Hassab group ${ }^{[33]}$. However, some studies have found that there is no relationship between different surgical methods and PVT formation ${ }^{[12]}$.

After splenectomy, reflux blood through the splenic vein almost disappears, and portal vein pressure and portal vein blood flow decrease by $20 \%-35 \%{ }^{[13]}$. If portal vein blood flow decreases sharply in the short-term, it will be easy for the portal vein to form eddies or other hemodynamic abnormalities, which is more likely to form a blood thrombus. In addition, after splenectomy, the distal end of the splenic vein becomes a dead end, which fosters blood retention, and the splenic vein thrombus is inclined to spread to the portal vein trunk ${ }^{[34]}$. Although devascularization blocks the collateral circulation of the portal vein and draws some of the blood back to the portal vein system, it is often not enough to make up for the blood loss of the portal vein after splenectomy. Some researchers recommend partial splenectomy (PS) or partial splenic embolization instead of splenectomy, because after PS or embolization, the blood flow velocity of the portal vein is higher in comparison with whole splenectomy, and besides, PS can retain the immune function of the spleen to some degree ${ }^{[35,36]}$. Some authors used an animal model of portal hypertension to determine the effect of PS, and after PS and intramuscular spleen transposition, portocaval collaterals developed and the portal venous pressure was reduced, while portocaval pressure difference was maintained to prevent deprivation of the liver. In a case report on the treatment of pediatric patients with portal hypertension, an 11-year-old girl underwent one-stage surgery, that is, PS with a view of transferring the remaining spleen to the thoracic cavity in the future. During follow-up, it was found that the patient's collateral circulation was well formed and that portal hypertension disappeared. The researchers believed that this case demonstrated that PS can be used as an alternative therapy to whole splenectomy ${ }^{[37]}$. Another clinical study on the treatment of extrahepatic portal vein occlusion in children showed that through distal spleen and kidney shunt and PS with $20 \%-30 \%$ spleen retention, the platelet and white blood cell counts of the patients returned to normal after operation, which indicates that shunt surgery plus PS is an effective and safe method for treating portal hypertension and hypersplenism ${ }^{[38]}$.

Nowadays, LS combined with devascularization or LS combined with shunt surgery is carried out in many hospitals. And, LS is considered to be more likely to cause PVT than open splenectomy. A clinical 
study revealed that PVT occurred in 12 (55\%) patients of the LS group, but in only 4 (19\%) of the open splenectomy group, and that LS leads to a higher incidence rate of PVT than does open splenectomy ${ }^{[39,40]}$. Due to hypercapnia caused by $\mathrm{CO}_{2}$, blood viscosity increases; in addition, blood flow velocity decreases with the positive pressure caused by pneumoperitoneum during the laparoscopic operation ${ }^{[13,41]}$. Consequently, from a certain perspective, open surgery has a relative preventive effect on PVT itself compared with $\mathrm{LS}^{[42]}$.

\section{Coagulation and anticoagulation disorder}

In the coagulation system of patients with liver cirrhosis, procoagulant factors and anticoagulant factors are in a dangerous equilibrium ${ }^{[43]}$; they are too complex and delicate to strike a balance: bleeding or thrombosis ${ }^{[44]}$, which may be disrupted by splenectomy, infection, acute renal failure, etc. ${ }^{[4]}$. Patients with cirrhosis are not sensitive or even resistant to thrombomodulin, and the blood coagulation state is higher in patients with Child-Pugh $\mathrm{C}$ than in patients with $\mathrm{A}_{\text {or }} \mathrm{B}^{[46]}$. It has been reported that a decrease in the levels of anticoagulant protein $\mathrm{C}$ and protein $\mathrm{S}$ can promote the pathogenesis of thrombosis, and in cirrhosis, the synthesis of protein $\mathrm{C}$ and $\mathrm{S}$ is impaired, so as cirrhosis worsens, factor VIII (procoagulant) increases, while protein $\mathrm{C}$, one of the anticoagulants decreases ${ }^{[46]}$; increased levels of factor VIII and decreased levels of protein $\mathrm{C}$ may be the major factors for $\mathrm{PVT}^{[47]}$. However, protein $\mathrm{C}$ and protein $\mathrm{S}$ in PVT might not be associated with PVT in liver cirrhosis, especially when the impact of liver function is excluded ${ }^{[48,49]}$.

Preoperative antithrombin III (AT-III) is an important risk factor for PVT, where the synthesis of it is reduced because of cirrhosis, and it is further reduced after splenectomy, leading to overconsumption of anticoagulants ${ }^{[50,51]}$. Some authors have demonstrated that prophylaxis with AT-III concentrates and danaparoid sodium after splenectomy can dramatically reduce the incidence of $\mathrm{PVT}^{[51]}$.

Prolonged prothrombin time (PT) is thought to be an independent factor in the occurrence of postoperative $\mathrm{PVT}^{[29]}$, but other researchers hold a different opinion that the formation of PVT has nothing to do with $\mathrm{PT}^{[52]}$, which may be so because traditional coagulation indicators do not reflect the true coagulation status of patients with liver cirrhosis ${ }^{[53]}$.

Fibrinogen can participate in the development of thrombosis ${ }^{[54]}$, and increased fibrinogen indicates a decrease in fibrinolytic activity and increases the incidence of thrombus ${ }^{[55]}$.

\section{Liver cirrhosis}

Different causes of liver cirrhosis lead to different PVT risks ${ }^{[56]}$. As decreased liver synthesis results in hypoproteinemia, extravasation of plasma water, and hypercoagulable blood concentration, it is easy to form thrombus in the portal vein system ${ }^{[57]}$. Because of the special pathophysiology of patients with liver cirrhosis, the incidence of PVT after splenectomy is higher ${ }^{[58]}$. A study showed that the incidence of PVT in patients with and without cirrhosis was $32.0 \%$ and $9.5 \%{ }^{[59]}$. Liver dysfunction can affect the formation of PVT by affecting the synthesis of coagulation factors, thrombin, albumin, etc. ${ }^{[1]}$. Studies show that ChildPugh scores are significantly higher in patients with postoperative PVT than in patients without $\mathrm{PVT}^{[60]}$. Meanwhile, incidence of PVT increases when MELD score is $\geq 13$ points ${ }^{[15]}$. Studies have shown the portal vein system rapidly forms a thrombus long before the improvement of liver function after splenectomy ${ }^{[41]}$, and some authors believe that traditional serological indicators (ALT, AST, etc.) have no relationship with PVT formation ${ }^{[52]}$, but ascites may be an important predictor of PVT, and albumin and hemoglobin decrease in cirrhotic patients significantly, which have potential value for the prediction ${ }^{[18,61]}$.

The occurrence and development of PVT has been shown to be related to the degree of esophageal varices ${ }^{[17]}$, which is caused by portal hypertension. Another study showed that the portal venous blood flow velocity in the severe gastroesophageal varices group was $(12.13 \pm 2.59) \mathrm{cm} / \mathrm{s}$, while in the non-severe gastroesophageal varices group, velocity was $(15.26 \pm 5.06) \mathrm{cm} / \mathrm{s}^{[62]}$. As is known to all, cirrhosis is an irreversible disease that 
continues to progress. The degree of cirrhosis worsens with time, and the occurrence of PVT is related to the severity of cirrhosis directly or indirectly.

\section{Platelet counts}

The enlarged spleen secretes related factors that inhibit platelet release from the marrow and reduces thrombopoietin during cirrhosis ${ }^{[63]}$. Once the spleen is removed, the suppression and clearance of platelets disappear, megakaryocytes proliferate in the marrow, causing platelets to skyrocket transiently. The formation of PVT might be associated with the soaring platelet count after operation ${ }^{[64]}$.

Preoperative decrease in platelet numbers is related to $\mathrm{PVT}^{[11]}$, the incidence of PVT in patients with PLT less than $50 \times 10^{9} / \mathrm{L}$ before surgery is significantly different from patients with PLT greater than $50 \times 10^{9} / \mathrm{L}^{[11]}$. And PLT is considered to be an independent risk factor for PVT after splenectomy ${ }^{[6,13,29]}$.

PLT often peaks at 3 to 20 days after splenectomy and gradually decreases to normal level. In one study, PVT was detected on the 6th day after surgery in patients whose PLT exceeded $200 \times 10^{9} / \mathrm{L}^{[29]}$. Researchers indicate that when the postoperative PLT exceeds $1000 \times 10^{9} / \mathrm{L}$, PVT is almost sure to take place ${ }^{[65]}$. The ratio of maximum postoperative PLT to preoperative PLT $(r=1.144 ; P=0.007)$ and PLT increasing to $>8$ times baseline levels after surgery are risk factors for PVT after $\mathrm{LS}^{[59]}$. Moreover, elevated platelets and D-dimers can cause atherosclerotic changes in blood vessels, and make the smooth muscles thick in the intima of the vein wall, thus causing fiber breakage, blood cell adhesion and formation of thrombi ${ }^{[11]}$.

However, thrombosis does not always occur in high PLT patients after splenectomy. Some studies have suggested that the function and quality of platelets have a greater impact on thrombosis than simple PLT elevation ${ }^{[64]}$. But this view is currently being challenged. In a prospective study, patients with PLT $>300 \times 10^{9} / \mathrm{L}$ after splenectomy were given antiplatelet therapy, namely aspirin, while the rest $<300 \times 10^{9} / \mathrm{L}$ were not given any antiplatelet therapy, and the results showed that there was no significant difference between the two groups $(7.0 \%$ vs. $16.1 \%, P=0.858)$, so the pathogenesis of PVT may have nothing to do with the function of platelets ${ }^{[29]}$. Some researchers regard primary thrombocytosis as the cause of thrombosis, rather than secondary thrombocytosis, and thrombocytosis after splenectomy is secondary thrombocytosis ${ }^{[6]}$.

Elevated PLT and mean platelet volume (MPV) after splenectomy have been considered to be the main cause of $\mathrm{PVT}^{[67-69]}$, and average platelet volume may also be a risk for PVT after surgery ${ }^{[69]}$. As for the large platelets, they are more active in metabolism and enzymatic reactions, and they contain more dense particles, $\alpha$-particles and highly active proteases. When larger platelets are activated, they can release more thrombus precursor material to induce thrombosis. Platelet membrane surface protein CD62P, also known as P-selectin, is an indicator of the degree of platelet activation and functional status. Some researchers have found that $\mathrm{CD} 62 \mathrm{P}$ can be used as a sensitive high-risk indicator of $\mathrm{PVT}^{[70]}$. Antiplatelet therapy should be adopted when PLT exceeds $1000 \times 10^{9} / \mathrm{L}^{[66]}$, and the consensus about this aspect has not been well established. Some clinicians believe that when the patient's PLT is $>400 \times 10^{9} / \mathrm{L}$, anticoagulation therapy should be started immediately $^{[71]}$. But for safety reasons, $>600 \times 10^{9} / \mathrm{L}$ may be a more suitable PLT to start the treatment.

\section{Level of D-dimer}

D-dimer mainly reflects lytic function. It is used in the diagnosis and prevention of many thrombotic diseases. The increase in D-dimer level is often associated with the enhanced lytic activity of secondary fibrin $^{[11]}$. D-dimer has been reported as a diagnostic marker for PVT ${ }^{[69]}$. In comparasion with PLT, D-dimer performs better in predicting thrombosis. Some studies suggest that the combined application of D-dimer and P-selectin can effectively diagnose PVT after splenectomy ${ }^{[72]}$. Like platelets, increased D-dimer after surgery can damage endothelial cells and cause PVT ${ }^{[11]}$. Based on the views of some authors, the evaluation of $\mathrm{D}$-dimer serologic levels is considered to own the adequate sensitivity and high negative predictive value 
in diagnosing thrombotic events ${ }^{[24,73]}$, but the reported low specificity rate is expected because D-dimer is elevated in different conditions, such as disseminated intravascular coagulation and sepsis ${ }^{[42,74,75]}$. However, the negative predictive value of the test is significant ${ }^{[42]}$. Negative test results will strengthen the diagnostic value of other aspects and the need for more specific studies will be minimal. D-dimer only reflects secondary fibrinolysis, and therefore, it can only have diagnostic value for the thrombosis that has occurred, and cannot be used as a predictor of PVT.

\section{Infection and inflammation}

The spleen can produce immune substances such as immunoglobulins and complements to play an immune role. In addition, the spleen also has the function of producing lymphocytes ${ }^{[76]}$. Splenectomized patients are at increased risk for infection, in particular, overwhelming post-splenectomy infection.

Infection and inflammation can cause a hypercoagulable state in the blood ${ }^{[77]}$. Infection-related and inflammation-induced coagulation activation is characterized by enhanced fibrin formation and impaired fibrin degradation, where enhanced fibrin formation is caused by tissue factor (TF)-mediated thrombin generation and inhibition of the anticoagulant system including proteins $\mathrm{C}$ and S. Inflammation increases circulating levels of plasminogen activator inhibitor type 1, which inhibits endogenous thrombolytic reactions, mediated by various pro-inflammatory cytokines ${ }^{[78]}$.

Studies have shown that inhibiting IL-6 almost eliminates the coagulation effect of the TF-dependent coagulation pathway $^{[79]}$. Monocytes stimulated by pro-inflammatory cytokines increase expression of TF in sepsis ${ }^{[80,81]}$. In inflammation, platelets can be directly activated by endotoxin or proinflammatory mediators (e.g., platelet activating factor). Platelets and granulocytes also can stimulate TF expression of monocytes by activated $\mathrm{NF}_{\kappa} \mathrm{B}^{[82]}$. The interactions between inflammatory cells promote the expression of IL-1b, IL- 8 , TNF- $\alpha$, and P-selectin, and they have a role in mediating the adhesion of platelets to endothelial cells.

\section{Other factors}

Among all cirrhotic patients, $80 \%-100 \%$ of them have malnutrition. Malnutrition will further increase liver damage, and exacerbate liver cirrhosis, so it can be seen as an indirect risk factor for $\mathrm{PVT}^{[83]}$.

Among patients with liver cirrhosis, $70 \%$ of them have gene mutations before or after splenectomy. It mainly includes prothrombin genes, coagulation factor genes and so on, which eventually make patients more prone to thrombosis ${ }^{[84]}$. For example, the G20210A mutation of the prothrombin gene has been found to play an important role in forming $\mathrm{PVT}^{[85]}$. Another study discovered that mutation rates of V-Leiden factor gene and prothrombin gene were higher in patients with PVT than in controls ${ }^{[86]}$, indicating that these genes may be related to the onset and development of PVT.

In addition, low white blood cell count $\left(\leq 2 \times 10^{3} / \mathrm{L}\right)$, upper gastric bleeding history, and some underlying diseases, such as hematologic diseases, are also thought to be independent risk factors for PVT $^{[6,42,52]}$.

Pathological changes occur in the vessel wall because of intravascular pressure, leading to "atherosclerosislike" changes. It is an important factor that leads to PVT. As endothelial lesions are gradually aggravated, the age of patients appears to be positively correlated with thrombosis. Older individuals are at increased risk for PVT, which is linked to age-specific pathophysiological characteristics, including decreased blood flow, endothelial injury, and hypercoagulability. Some authors have pointed out that $>50$ years old might be an independent risk factor for PVT. Patients who are over 50 are more than 20 times likely to suffer from PVT than those younger ${ }^{[13]}$.

Pancreatic fistula was reported as an independent risk factor for the development of PVT after the Hassab operation $^{[87]}$. The reason may be that pancreatic fistula causes prolonged hospital stay for the patient and increases the patient's bed time. 


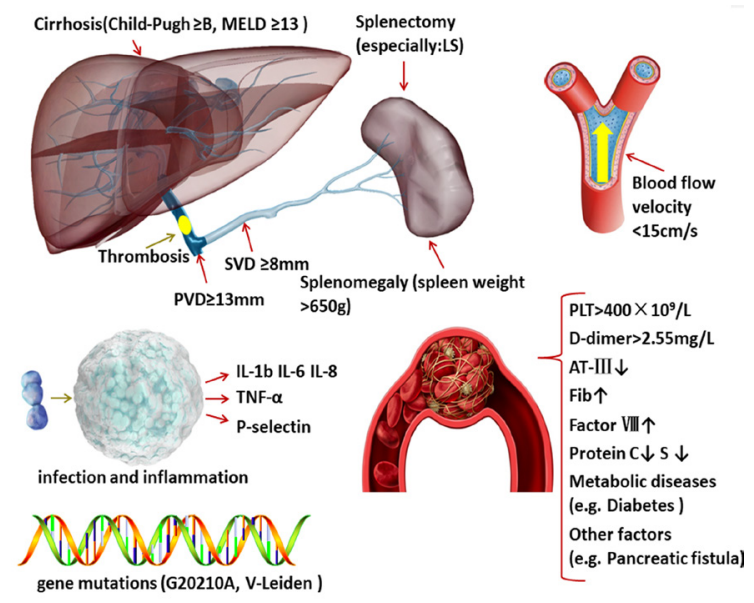

Figure 1. A preliminary summary of risk factors for portal vein thrombosis after splenectomy in patients with liver cirrhosis. SVD: splenic vein diameter; LS: laparoscopic splenectomy

A series of diseases, such as high blood lipids, high cholesterol and obesity, may also be risk factors for PVT formation. Still, some authors do not consider obesity to be associated with $\mathrm{PVT}^{[88]}$. Another metabolic disease, diabetes, may be an independent risk factor for PVT in cirrhosis ${ }^{[89]}$. This may be due to excessive blood glucose concentration, damaging the vascular endothelium. Therefore, blood glucose should also be regularly screened for thrombosis perioperatively.

There are many other medical factors that promote PVT, for instance, esophageal gastric varices sclerosis treatment, use of postoperative diuretics, and percutaneous transhepatic portal vein puncture.

Moreover, primary liver cancer can aggravate portal hypertension and change portal vein hemodynamics ${ }^{[90]}$. In summary, the relevant risk factors are listed in Figure 1.

\section{PROPHYLAXIS AND TREATMENTS}

Today, we have clear guidelines or consensus on the prevention of deep vein thrombosis and pulmonary embolism after operation ${ }^{[11]}$. However, there is no clear effective guidelines or consensus on PVT. Our management of PVT mainly relies on our clinical experience. Once the diagnosis is clear, all patients should be proactively treated except for asymptomatic incomplete embolism.

\section{Medical treatment}

Since the occurrence and development of PVT is likely to start before the operation, attention should be paid to early preventive anticoagulation. Anticoagulation plays a key role in preventing the formation of PVT, improving liver function, and reducing mortality ${ }^{[91]}$. Low-molecular weight heparin (LMWH), warfarin, lowmolecular weight dextran and bayaspirin are used to treat PVT in clinical practice. Some researchers have proposed that AT-III is also an approach to prevent PVT ${ }^{[51]}$. Currently, interventional infusion thrombolytic drugs for thrombolysis have been used for $\mathrm{PVT}^{[92]}$.

LMWH can inhibit the activation of factor Xa and the formation of thrombus by binding AT-III ${ }^{[93]}$, and LMWH has a strong antithrombotic effect with less effect on platelet function, and does not prolong bleeding time ${ }^{[94]}$. Studies have suggested that the use of LMWH at an early stage can significantly and safely reduce the incidence of PVT after splenectomy ${ }^{[95]}$. Early use of LMWH contributes to thrombosis recanalization, and treatment should be started within 14 days of the discovery of thrombus ${ }^{[96]}$. Some researchers have even suggested that all patients undergoing splenectomy should be prophylactically given low-molecular weight heparin ${ }^{[42]}$. In authors' view, routine use of anticoagulant or antiplatelet drugs in the short-term after 
splenectomy for cirrhosis does not increase the risk of postoperative bleeding and can effectively prevent PVT. At the same time, antiplatelet drugs should be used until PLT has fallen to normal levels. The specific application methods are described as follows. Anticoagulation should be applied at $72 \mathrm{~h}$ after surgery for safety concerns. Either LMWH-calcium or LMWH-sodium can be used. Taking enoxheparin ( $0.4 \mathrm{~mL}$, $4000 \mathrm{AXa} I U, \mathrm{ih}, \mathrm{qd})$ as an example, the duration of treatment is 5 days. After discontinuation of enoxaparin, oral warfarin is used for continuous anticoagulation for 6 months. INR should be maintained between 2 and 3. When platelets exceed $400 \times 10^{9} / \mathrm{L}$, antiplatelet drugs, such as aspirin, ticlopidine or dipyridamole should be used. After the platelets have returned to normal values, they should be discontinued. PLT and coagulation states of patients should be monitored every other day in the first week, and then monthly in the first year after surgery. Color Doppler ultrasound should be repeated monthly in the first year. It is worth noting that for PVT patients with mild to moderate renal dysfunction, the dose of enoxaparin should be halved, and liver and kidney function should be closely monitored. In patients with severe renal dysfunction or renal failure, enoxaparin must be used with caution according to the specific situation.

Warfarin inhibits the synthesis of vitamin K-dependent coagulation factors II, VII, IX, and $\mathrm{X}^{[41]}$. Studies have shown that prophylactic anticoagulation is effective and safe in patients undergoing splenectomy, and that warfarin is effective in patients undergoing $\mathrm{LS}^{[1,97]}$. But warfarin can also inhibit the synthesis of proteins $\mathrm{C}$ and $\mathrm{S}$, and thus, it has the potential to increase thrombosis ${ }^{[98]}$. Rivaroxaban and Dabigatran are approved for clinical use, and these drugs are widely used since there is no need for dose adjustment. Rivaroxaban has been successfully used to treat PVT according to some reports ${ }^{[99,100]}$. Studies have shown that for patients with cirrhosis, the anticoagulant effect of dabigatran is very considerable, while the anticoagulant effect of rivaroxaban is slightly weaker ${ }^{[101]}$.

However, some researchers warn that considering that the rethrombosis rate after anticoagulation therapy is still high (52\%), long-term anticoagulation should be applied more carefully ${ }^{[102]}$. At present, most of the research on the prevention of PVT focuses on LMWH because it has a good anticoagulant effect, but to date, there is no uniform standard for applying $\mathrm{LMWH}$ to $\mathrm{PVT}^{[103]}$.

\section{Surgery and interventional treatment}

For PVT after splenectomy, when non-invasive treatment of thrombosis fails and causes portal vein stenosis, invasive treatment can be considered: surgery and interventional treatment.

Surgical treatments are mostly performed with clear serious complications, but there is still no unified standard for the indications, surgical choices, contraindications and complications of surgery. There are three main types of interventional therapies for PVT: TIPS, percutaneous transhepatic portal vein thrombolysis or thrombectomy. One of the most common treatments is TIPS, where it can improve portal vein hemodynamics and dissolve fluid clot ${ }^{[104]}$. Portal vein flow increases more than 5 times after TIPS ${ }^{[105]}$. Moreover, PVT can also be treated directly by intravascular techniques (balloon angioplasty, stent placement, thrombectomy, and thrombolytic drugs) when the catheter is inserted into the portal vein ${ }^{[106]}$. TIPS can play an active role in resolving portal hypertension and preventing the recurrence of blood clots by creating venous shunts ${ }^{[107]}$. Portal recanalization can be achieved in $87 \%$ to $100 \%$ of patients by TIPS ${ }^{[106,108]}$. However, the timing of TIPS treatment is a tough issue. A complete occlusion of the thrombus will significantly increase the technical difficulty and surgical risk of TIPS ${ }^{[109]}$. Futher studies are required to solve this problem.

In addition, some researchers have proposed autologous spleen transplantation combined with esophageal transection anastomosis to treat cirrhotic portal hypertension. After 2 months of operation, patients with autologous spleen transplantation had significantly higher levels of tuftsin and IgM than splenectomy patients, and there was no significant difference in liver function, which proves that autologous spleen transplantation combined with esophageal transection anastomosis is a safe and effective treatment strategy for the treatment 
of cirrhotic portal hypertension, and that the transplantation of spleen tissue into the retroperitoneal cavity can partially retain immune function ${ }^{[10]}$. The cited researchers believe that this operation can not only retain the function of the spleen, but also has a combined effect of blood flow cut-off and diversion when the collateral circulation is well formed ${ }^{[111]}$. Some authors believe that the autotransplantation of the spleen must weigh over $50 \mathrm{~g}$ to retain the immune function of the spleen, but when the spleen was cut into 8 small pieces, 23-28 g/piece, and transplanted in the omentum, the postoperative infection rate did not increase, and complement and immunoglobulin were normal, indicating that this procedure also has a certain therapeutic effect $^{[112]}$.

\section{CONCLUSION}

PVT is the most important complication that affects the prognosis of patients after splenectomy, which may further aggravate portal hypertension and cause postoperative bleeding. Therefore, attention should be paid to preoperative prediction and evaluation, intraoperative improvement of surgical methods, timely postoperative monitoring and prevention. Clinicians should be fully aware of all aspects of a patient's illness, such as the etiology, classification, degree of obstruction, comorbidities of postoperative PVT, etc. Of course, there is still much controversy about the understanding of risk factors of PVT after splenectomy. Therefore, multidisciplinary randomized controlled trials are needed.

\section{DECLARATIONS}

\section{Authors' contributions}

Made substantial contributions to the conception and design of the study and interpretation of results: Yang ZL

Contributed to the article and Figure: Guo T

Performed literature collection and provided technical suggestions as well: Zhu DL, Zheng S, Han DD

Put forward targeted opinions on the content, and control the quality of manuscripts: Chen Y

\section{Availability of data and materials}

All data are fully available without restriction.

\section{Financial support and sponsorship}

None.

\section{Conflicts of interest}

All authors declared that there are no conflicts of interest.

\section{Ethical approval and consent to participate}

Not applicable.

\section{Consent for publication}

Not applicable.

\section{Copyright}

(c) The Author(s) 2020.

\section{REFERENCES}

1. Zhang X, Wang Y, Yu M, Huang J, Deng D, et al. Effective prevention for portal venous system thrombosis after splenectomy: a metaanalysis. J Laparoendosc Adv Surg Tech A 2017;27:247-52.

2. Hashizume M, Tomikawa M, Akahoshi T, Tanoue K, Gotoh N, et al. Laparoscopic splenectomy for portal hypertension. Hepatogastroenterology 2002;49:847-52. 
3. Raja K, Jacob M, Asthana S. Portal vein thrombosis in cirrhosis. J Clin Exp Hepatol 2014;4:320-31.

4. Targarona EM. Portal vein thrombosis after laparoscopic splenectomy: the size of the risk. Surg Innov 2008;15:266-70.

5. Krauth MT, Lechner K, Neugebauer EA, Pabinger I. The postoperative splenic/portal vein thrombosis after splenectomy and its prevention - an unresolved issue. Haematologica 2008;93:1227-32.

6. Kinjo N, Kawanaka H, Akahoshi T, Tomikawa M, Yamashita N, et al. Risk factors for portal venous thrombosis after splenectomy in patients with cirrhosis and portal hypertension. Br J Surg 2010;97:910-6.

7. Yoshida M, Watanabe Y, Horiuchi A, Yamamoto Y, Sugishita H, et al. Portal and splenic venous thrombosis after splenectomy in patients with hypersplenism. Hepatogastroenterology 2009;56:538-41.

8. Xu X, Guo X, De Stefano V, Silva-Junior G, Goyal H, et al. Nonselective beta-blockers and development of portal vein thrombosis in liver cirrhosis: a systematic review and meta-analysis. Hepatol Int 2019;13:468-81.

9. Huang XL, Wang FH, Zhang JK. Risk factors of portal vein thrombosis after surgery for advanced schistosomiasis portal hypertension. Zhongguo Xue Xi Chong Bing Fang Zhi Za Zhi 2015;27:177-9. (in Chinese)

10. Kuroki T, Kitasato A, Tokunaga T, Takeshita H, Taniguchi K, et al. Predictors of portal and splenic vein thrombosis after laparoscopic splenectomy: a retrospective analysis of a single-center experience. Surg Today 2018;48:804-9.

11. Wu S, Wu Z, Zhang X, Wang R, Bai J. The incidence and risk factors of portal vein system thrombosis after splenectomy and pericardial devascularization. Turk J Gastroenterol 2015;26:423-8.

12. Harding DJ, Perera MT, Chen F, Olliff S, Tripathi D. Portal vein thrombosis in cirrhosis: controversies and latest developments. World J Gastroenterol 2015;21:6769-84.

13. Jiang GQ, Bai DS, Chen P, Qian JJ, Jin SJ, et al. Risk factors for portal vein system thrombosis after laparoscopic splenectomy in cirrhotic patients with hypersplenism. J Laparoendosc Adv Surg Tech A 2016;26:419-23.

14. Qi X, Li H, Liu X, Yao H, Han G, et al. Novel insights into the development of portal vein thrombosis in cirrhosis patients. Expert Rev Gastroenterol Hepatol 2015;9:1421-32.

15. Zocco MA, Di Stasio E, De Cristofaro R, Novi M, Ainora ME, et al. Thrombotic risk factors in patients with liver cirrhosis: correlation with MELD scoring system and portal vein thrombosis development. J Hepatol 2009;51:682-9.

16. Huang L, Yu Q, Wang J. Association between changes in splanchnic hemodynamics and risk factors of portal venous system thrombosis after splenectomy with periesophagogastric devascularization. Med Sci Monit 2018;24:4355-62.

17. Nery F, Chevret S, Condat B, de Raucourt E, Boudaoud L, et al. Groupe d'Etude et de Traitement du Carcinome H. Causes and consequences of portal vein thrombosis in 1,243 patients with cirrhosis: results of a longitudinal study. Hepatology 2015;61:660-7.

18. Abdel-Razik A, Mousa N, Elhelaly R, Tawfik A. De-novo portal vein thrombosis in liver cirrhosis: risk factors and correlation with the model for end-stage liver disease scoring system. Eur J Gastroenterol Hepatol 2015;27:585-92.

19. Trebicka J, Strassburg CP. Etiology and complications of portal vein thrombosis. Viszeralmedizin 2014;30:375-80.

20. Dai J, Qi X, Peng Y, Hou Y, Chen J, et al. Association between D-dimer level and portal venous system thrombosis in liver cirrhosis: a retrospective observational study. Int J Clin Exp Med 2015;8:15296-301.

21. Bolognesi M, Merkel C, Sacerdoti D, Nava V, Gatta A. Role of spleen enlargement in cirrhosis with portal hypertension. Dig Liver Dis 2002;34:144-50.

22. McCormick PA, Murphy KM. Splenomegaly, hypersplenism and coagulation abnormalities in liver disease. Baillieres Best Pract Res Clin Gastroenterol 2000;14:1009-31.

23. Romano A, Hou X, Sertorio M, Dessein H, Cabantous S, et al. FOXP3+ regulatory T cells in hepatic fibrosis and splenomegaly caused by schistosoma japonicum: the spleen may be a major source of tregs in subjects with splenomegaly. PLoS Negl Trop Dis 2016;10:e0004306.

24. Stamou KM, Toutouzas KG, Kekis PB, Nakos S, Gafou A, et al. Prospective study of the incidence and risk factors of postsplenectomy thrombosis of the portal, mesenteric, and splenic veins. Arch Surg 2006;141:663-9.

25. Wang M, Zhang M, Li J, Zhou J, Wu Z, et al. Risk factors of portal vein thrombosis in patients with beta thalassemia major after splenectomy: laparoscopic versus open procedure. Hepatogastroenterology 2014;61:48-54.

26. Ikeda M, Sekimoto M, Takiguchi S, Kubota M, Ikenaga M, et al. High incidence of thrombosis of the portal venous system after laparoscopic splenectomy: a prospective study with contrast-enhanced CT scan. Ann Surg 2005;241:208-16.

27. Pietrabissa A, Moretto C, Antonelli G, Morelli L, Marciano E, et al. Thrombosis in the portal venous system after elective laparoscopic splenectomy. Surg Endosc 2004;18:1140-3.

28. Danno K, Ikeda M, Sekimoto M, Sugimoto T, Takemasa I, et al. Diameter of splenic vein is a risk factor for portal or splenic vein thrombosis after laparoscopic splenectomy. Surgery 2009;145:457-64; discussion 65-6.

29. Li MX, Zhang XF, Liu ZW, Lv Y. Risk factors and clinical characteristics of portal vein thrombosis after splenectomy in patients with liver cirrhosis. Hepatobiliary Pancreat Dis Int 2013;12:512-9.

30. Sun L, Zhou H, Gu L, Jiang C, Liu Y, et al. Effects of surgical procedures on the occurrence and development of postoperative portal vein thrombosis in patients with cirrhosis complicated by portal hypertension. Int J Surg 2015;16:31-5.

31. Bai DS, Xia BL, Zhang C, Ye J, Qian JJ, et al. Warfarin versus aspirin prevents portal vein thrombosis after laparoscopic splenectomy and azygoportal disconnection: A randomized clinical trial. Int J Surg 2019;64:16-23.

32. Zheng S, Sun P, Liu X, Li G, Gong W, et al. Efficacy and safety of laparoscopic splenectomy and esophagogastric devascularization for portal hypertension: a single-center experience. Medicine 2018;97:e13703.

33. Bao H, He Q, Dai N, Ye R, Zhang Q. Retrospective study to compare selective decongestive devascularization and gastrosplenic shunt versus splenectomy with pericardial devascularization for the treatment of patients with esophagogastric varices due to cirrhotic portal hypertension. Med Sci Monit 2017;23:2788-95. 
34. de'Angelis N, Abdalla S, Lizzi V, Esposito F, Genova P, et al. Incidence and predictors of portal and splenic vein thrombosis after pure laparoscopic splenectomy. Surgery 2017;162:1219-30.

35. Eyraud D, Granger B, Ionescu C, Fratea S, Darnat S, et al. Thrombocytopenia, splenomegaly, and portal blood flow in patients who have undergone liver transplantation for cirrhosis. Liver Transpl 2012;18:340-6.

36. Guan YS, Hu Y. Clinical application of partial splenic embolization. Sci World J 2014;2014:961345.

37. Kheradpir MH. Partial splenectomy and partial splenic attachment for the treatment of portal hypertension. Z Kinderchir 1990;45:98-9.

38. Sretenovic A, Perisic V, Vujovic D, Opacic D, Vukadinovic V, et al. Warren shunt combined with partial splenectomy in children with extra-hepatic portal hypertension, massive splenomegaly and severe hypersplenism. Srp Arh Celok Lek 2014;142:419-23.

39. Zhe C, Jian-Wei L, Jian C, Yu-dong F, Ping B, et al. Laparoscopic versus open splenectomy and esophagogastric devascularization for bleeding varices or severe hypersplenism: a comparative study. J Gastrointest Surg 2013;17:654-9.

40. Stine JG, Shah PM, Cornella SL, Rudnick SR, Ghabril MS, et al. Portal vein thrombosis, mortality and hepatic decompensation in patients with cirrhosis: a meta-analysis. World J Hepatol 2015;7:2774-80.

41. Jiang GQ, Xia BL, Chen P, Qian JJ, Jin SJ, et al. Anticoagulation therapy with warfarin versus low-dose aspirin prevents portal vein thrombosis after laparoscopic splenectomy and azygoportal disconnection. J Laparoendosc Adv Surg Tech A 2016;26:517-23.

42. Vecchio R, Cacciola E, Cacciola RR, Marchese S, Intagliata E. Portal vein thrombosis after laparoscopic and open splenectomy. J Laparoendosc Adv Surg Tech A 2011;21:71-5.

43. Leonardi F, Maria N, Villa E. Anticoagulation in cirrhosis: a new paradigm? Clin Mol Hepatol 2017;23:13-21.

44. Monroe DM, Hoffman M. The coagulation cascade in cirrhosis. Clin Liver Dis 2009;13:1-9.

45. Primignani M, Tosetti G, La Mura V. Therapeutic and clinical aspects of portal vein thrombosis in patients with cirrhosis. World J Hepatol 2015;7:2906-12.

46. Tripodi A, Primignani M, Chantarangkul V, Dell'Era A, Clerici M, et al. An imbalance of pro- vs anti-coagulation factors in plasma from patients with cirrhosis. Gastroenterology 2009;137:2105-11.

47. Tripodi A, Primignani M, Lemma L, Chantarangkul V, Mannucci PM. Evidence that low protein C contributes to the procoagulant imbalance in cirrhosis. J Hepatol 2013;59:265-70.

48. Qi X, Chen H, Han G. Effect of antithrombin, protein C and protein S on portal vein thrombosis in liver cirrhosis: a meta-analysis. Am J Med Sci 2013;346:38-44.

49. Rodriguez-Leal GA, Moran S, Corona-Cedillo R, Brom-Valladares R. Portal vein thrombosis with protein C-S deficiency in a noncirrhotic patient. World J Hepatol 2014;6:532-7.

50. Kawanaka H, Akahoshi T, Kinjo N, Konishi K, Yoshida D, et al. Impact of antithrombin III concentrates on portal vein thrombosis after splenectomy in patients with liver cirrhosis and hypersplenism. Ann Surg 2010;251:76-83.

51. Kawanaka H, Akahoshi T, Itoh S, Iguchi T, Harimoto N, et al. Optimizing risk stratification in portal vein thrombosis after splenectomy and its primary prophylaxis with antithrombin III concentrates and danaparoid sodium in liver cirrhosis with portal hypertension. J Am Coll Surg 2014;219:865-74.

52. Han J, Yi Y, Ding H, Liu J, Zhang Y, et al. Preoperative risk factors of portal venous thrombosis after splenectomy and gastric pericardial devascularization for portal hypertension. Zhonghua Gan Zang Bing Za Zhi 2014;22:739-43. (in Chinese)

53. Zhang Y, Wen TF, Yan LN, Yang HJ, Deng XF, et al. Preoperative predictors of portal vein thrombosis after splenectomy with periesophagogastric devascularization. World J Gastroenterol 2012;18:1834-9.

54. Rossetto V, Spiezia L, Senzolo M, Rodriguez-Castro KI, Gavasso S, et al. Does decreased fibrinolysis have a role to play in the development of non-neoplastic portal vein thrombosis in patients with hepatic cirrhosis? Intern Emerg Med 2014;9:397-403.

55. Smalberg JH, Koehler E, Darwish Murad S, Plessier A, Seijo S, et al. European Network for Vascular Disorders of the L. Fibrinogen gamma' and variation in fibrinogen gamma genes in the etiology of portal vein thrombosis. Thromb Haemost 2013;109:558-60.

56. Kinjo N, Kawanaka H, Akahoshi T, Matsumoto Y, Kamori M, et al. Portal vein thrombosis in liver cirrhosis. World J Hepatol 2014;6:6471.

57. Qi X, Su C, Ren W, Yang M, Jia J, et al. Association between portal vein thrombosis and risk of bleeding in liver cirrhosis: a systematic review of the literature. Clin Res Hepatol Gastroenterol 2015;39:683-91.

58. Zhang N, Yao Y, Xue W, Wu S. Early prophylactic anticoagulation for portal vein system thrombosis after splenectomy: a systematic review and meta-analysis. Biomed Rep 2016;5:483-90.

59. Huang D, Tao M, Cao L, Wang X, Zheng S, et al. Risk factors and anticoagulation effects of portal vein system thrombosis after laparoscopic splenectomy in patients with or without cirrhosis. Surg Laparosc Endosc Percutan Tech 2019;29:498-502.

60. Nadinskaia MY, Kodzoeva KB, Ulyanova KA, Volkova AS, Rogacheva SI, et al. Risk factors associated with portal vein thrombosis in liver cirrhosis: a case-control study. Ter Arkh 2019;91:73-81.

61. Hernandez Conde M, Llop Herrera E, de la Revilla Negro J, Pons Renedo F, Fernandez Puga N, et al. Prevalence and outcome of portal thrombosis in a cohort of cirrhotic patients undergoing liver transplantation. Rev Esp Enferm Dig 2016;108:716-20.

62. Tarzamni MK, Somi MH, Farhang S, Jalilvand M. Portal hemodynamics as predictors of high risk esophageal varices in cirrhotic patients. World J Gastroenterol 2008;14:1898-902.

63. Chawla YK, Bodh V. Portal vein thrombosis. J Clin Exp Hepatol 2015;5:22-40.

64. Francoz C, Valla D, Durand F. Portal vein thrombosis, cirrhosis, and liver transplantation. J Hepatol 2012;57:203-12.

65. Machado NO, Chopra PJ, Sankhla D. Portal vein thrombosis postlaparoscopic splenectomy presenting with infarction of gut: review of risk factors, investigations, postoperative surveillance, and management. Surg Laparosc Endosc Percutan Tech 2010;20:273-7.

66. Griesshammer M, Bangerter M, Sauer T, Wennauer R, Bergmann L, et al. Aetiology and clinical significance of thrombocytosis: analysis 
of 732 patients with an elevated platelet count. J Intern Med 1999;245:295-300.

67. Coppinger JA, Cagney G, Toomey S, Kislinger T, Belton O, et al. Characterization of the proteins released from activated platelets leads to localization of novel platelet proteins in human atherosclerotic lesions. Blood 2004;103:2096-104.

68. Ghanima W, Godeau B, Cines DB, Bussel JB. How I treat immune thrombocytopenia: the choice between splenectomy or a medical therapy as a second-line treatment. Blood 2012;120:960-9.

69. He S, He F. Predictive model of portal venous system thrombosis in cirrhotic portal hypertensive patients after splenectomy. Int J Clin Exp Med 2015;8:4236-42.

70. Wang L, Liu GJ, Chen YX, Dong HP, Zhang YQ, et al. Combined use of D-dimer and P-selectin for the diagnosis of splenic or portal vein thrombosis following splenectomy. Thromb Res 2010;125:e206-9.

71. Hirashita T, Ohta M, Kai S, Masuda T, Eguchi H, et al. Implications of portal vein thrombosis after splenectomy for patients with idiopathic portal hypertension. Surg Today 2011;41:1475-80.

72. Qi X, De Stefano V, Li H, Dai J, Guo X, et al. Anticoagulation for the treatment of portal vein thrombosis in liver cirrhosis: a systematic review and meta-analysis of observational studies. Eur J Intern Med 2015;26:23-9.

73. Bates SM, Grand'Maison A, Johnston M, Naguit I, Kovacs MJ, et al. A latex D-dimer reliably excludes venous thromboembolism. Arch Intern Med 2001;161:447-53.

74. Shorr AF, Thomas SJ, Alkins SA, Fitzpatrick TM, Ling GS. D-dimer correlates with proinflammatory cytokine levels and outcomes in critically ill patients. Chest 2002;121:1262-8.

75. Kinasewitz GT, Yan SB, Basson B, Comp P, Russell JA, et al. Universal changes in biomarkers of coagulation and inflammation occur in patients with severe sepsis, regardless of causative micro-organism [ISRCTN74215569]. Crit Care 2004;8:R82-90.

76. Di Sabatino A, Carsetti R, Corazza GR. Post-splenectomy and hyposplenic states. Lancet 2011;378:86-97.

77. Levi M, Sivapalaratnam S. Disseminated intravascular coagulation: an update on pathogenesis and diagnosis. Expert Rev Hematol 2018;11:663-72.

78. Levi M, van der Poll T, ten Cate H, van Deventer SJ. The cytokine-mediated imbalance between coagulant and anticoagulant mechanisms in sepsis and endotoxaemia. Eur J Clin Invest 1997;27:3-9.

79. van der Poll T, Levi M, Hack CE, ten Cate H, van Deventer SJ, et al. Elimination of interleukin 6 attenuates coagulation activation in experimental endotoxemia in chimpanzees. J Exp Med 1994;179:1253-9.

80. Osterud B, Rao LV, Olsen JO. Induction of tissue factor expression in whole blood: lack of evidence for the presence of tissue factor expression in granulocytes. Thromb Haemost 2000;83:861-7.

81. Franco RF, de Jonge E, Dekkers PE, Timmerman JJ, Spek CA, et al. The in vivo kinetics of tissue factor messenger RNA expression during human endotoxemia: relationship with activation of coagulation. Blood 2000;96:554-9.

82. Furie B, Furie BC. Role of platelet P-selectin and microparticle PSGL-1 in thrombus formation. Trends Mol Med 2004;10:171-8.

83. Campillo B, Richardet JP, Bories PN. Validation of body mass index for the diagnosis of malnutrition in patients with liver cirrhosis. Gastroenterol Clin Biol 2006;30:1137-43.

84. Ponziani FR, Zocco MA, Campanale C, Rinninella E, Tortora A, et al. Portal vein thrombosis: insight into physiopathology, diagnosis, and treatment. World J Gastroenterol 2010;16:143-55.

85. Amitrano L, Guardascione MA, Brancaccio V, Margaglione M, Manguso F, et al. Risk factors and clinical presentation of portal vein thrombosis in patients with liver cirrhosis. J Hepatol 2004;40:736-41.

86. Dentali F, Galli M, Gianni M, Ageno W. Inherited thrombophilic abnormalities and risk of portal vein thrombosis. a meta-analysis. Thromb Haemost 2008;99:675-82.

87. Zhou JB, Luo BY, Liu CW, Zhu F. Effects of early antiplatelet therapy after splenectomy with gastro-oesophageal devascularization. ANZ J Surg 2018;88:E725-9.

88. Zakko A, Kroner PT, Nankani R, Karagozian R. Obesity is not associated with an increased risk of portal vein thrombosis in cirrhotic patients. Gastroenterol Hepatol Bed Bench 2018;11:153-8.

89. Eshraghian A, Nikeghbalian S, Kazemi K, Mansoorian M, Shamsaeefar A, et al. Portal vein thrombosis in patients with liver cirrhosis and its impact on early and long-term outcomes after liver transplantation. Int J Clin Pract 2018; 13309.

90. Hu KQ, Yu AS, Tiyyagura L, Redeker AG, Reynolds TB. Hyperfibrinolytic activity in hospitalized cirrhotic patients in a referral liver unit. Am J Gastroenterol 2001;96:1581-6.

91. Villa E, Camma C, Marietta M, Luongo M, Critelli R, et al. Enoxaparin prevents portal vein thrombosis and liver decompensation in patients with advanced cirrhosis. Gastroenterology 2012;143:1253-60.e4.

92. Valentin N, Korrapati P, Constantino J, Young A, Weisberg I. The role of transjugular intrahepatic portosystemic shunt in the management of portal vein thrombosis: a systematic review and meta-analysis. Eur J Gastroenterol Hepatol 2018;30:1187-93.

93. Romualdi E, Ageno W. Investigational factor Xa inhibitors for thrombosis and acute coronary syndromes. Expert Opin Investig Drugs 2011;20:495-505.

94. Millan M, Caicedo LA, Villegas JI, Serrano O, Caicedo L, et al. Case report of cadaveric kidney transplantation with renal-portal venous drainage: a feasible way for a venous drainage in a complex generalized thrombosed vessels setting. Int J Surg Case Rep 2016;28:192-5.

95. Lai W, Lu SC, Li GY, Li CY, Wu JS, et al. Anticoagulation therapy prevents portal-splenic vein thrombosis after splenectomy with gastroesophageal devascularization. World J Gastroenterol 2012;18:3443-50.

96. Delgado MG, Seijo S, Yepes I, Achecar L, Catalina MV, et al. Efficacy and safety of anticoagulation on patients with cirrhosis and portal vein thrombosis. Clin Gastroenterol Hepatol 2012;10:776-83.

97. Cheng Z, Yu F, Tian J, Guo P, Li J, et al. A comparative study of two anti-coagulation plans on the prevention of PVST after laparoscopic 
splenectomy and esophagogastric devascularization. J Thromb Thrombolysis 2015;40:294-301.

98. Tripodi A, Mannucci PM. The coagulopathy of chronic liver disease. N Engl J Med 2011;365:147-56.

99. Lenz K, Dieplinger B, Buder R, Piringer P, Rauch M, et al. Successful treatment of partial portal vein thrombosis (PVT) with low dose rivaroxaban. Z Gastroenterol 2014;52:1175-7.

100. Yang H, Kim SR, Song MJ. Recurrent acute portal vein thrombosis in liver cirrhosis treated by rivaroxaban. Clin Mol Hepatol 2016;22:499-502.

101. Potze W, Arshad F, Adelmeijer J, Blokzijl H, van den Berg AP, et al. Differential in vitro inhibition of thrombin generation by anticoagulant drugs in plasma from patients with cirrhosis. PLoS One 2014;9:e88390.

102. Artaza T, Lopes M, Romero M, Gomez AZ, de la Cruz G, et al. Efficacy and safety of anticoagulation in non-malignant portal vein thrombosis in patients with liver cirrhosis. Gastroenterol Hepatol 2018;41:611-7.

103. Qi X, Han G, Wang J, Wu K, Fan D. Degree of portal vein thrombosis. Hepatology 2010;51:1089-90.

104. Senzolo M, M Sartori T, Rossetto V, Burra P, Cillo U, et al. Prospective evaluation of anticoagulation and transjugular intrahepatic portosystemic shunt for the management of portal vein thrombosis in cirrhosis. Liver Int 2012;32:919-27.

105. Gaba RC, Parvinian A. Transjugular intrahepatic portosystemic shunt for maintenance of portal venous patency in liver transplant candidates. J Clin Imaging Sci 2013;3:28.

106. Lakhoo J, Gaba RC. Outcomes of transjugular intrahepatic portosystemic shunt creation for flow-enabled dissolution of splenomesenterico-portal venous thrombosis. Diagn Interv Imaging 2016;97:1085-93.

107. Riggio O, Ridola L, Lucidi C, Angeloni S. Emerging issues in the use of transjugular intrahepatic portosystemic shunt (TIPS) for management of portal hypertension: time to update the guidelines? Dig Liver Dis 2010;42:462-7.

108. Inagaki Y, Sugimoto K, Shiraki K, Tameda M, Kusagawa S, et al. The long-term effects of splenectomy and subsequent interferon therapy in patients with HCV-related liver cirrhosis. Mol Med Rep 2014;9:487-92.

109. Yang S, He C, Fan X, Ding W, Wu X, et al. Early prophylactic anticoagulation via transjugular intrahepatic route for portal vein thrombosis after splenectomy in cirrhotic portal hypertension. J Vasc Interv Radiol 2015;26:1009-17.

110. Shang CZ, Chen YJ, Zhang HW, Zhang L, Cao J, et al. Splenic autotransplantation combined with lower esophagus transaction in the treatment of hepatic cirrhosis induced portal hypertension. Zhonghua Wai Ke Za Zhi 2009;47:83-5. (in Chinese)

111. Shan HJ, Ji-Sheng C, Zhuo W, Rufu C, Zhihao Z, et al. Portal veinous hemodynamics after subtotal splenectomy and portaazygous devascularization. Zhongguo Putong Waike Zazhi 2010;25:20-3.

112. Zhu Y. Analysis of 26 cases of autotransplantation of spleen tissue after splenectomy. Clin Med Chin 2004;20:459-60. (in Chinese) 